\title{
A mulher idosa nos contos infantis: Os estereótipos da velhice e a violência simbólica
}

\section{The elderly woman in children's tales: Stereotypes of old age and symbolic violence}

La mujer mayor de los cuentos infantiles: Estereotipos de la vejez y violencia simbólica

Nádia Sampaio ${ }^{1}$ https://orcid.org/0000-0002-5455-5058

Luana de Araújo dos Reis ${ }^{2}$ https://orcid.org/0000-0002-9263-083X

Luciana Araújo dos Reis ${ }^{3}$ https://orcid.org/0000-0002-0867-8057

\footnotetext{
${ }^{1}$ PPGMLS- Universidade Estadual do Sudoeste da Bahia - UESB- Brasil /Instituto Federal da Bahia- IFBA-Vitória da ConquistaBahia-Brasil .E-mail: ndiasampaio@yahoo.com.br

${ }^{2}$ Faculadade Independente do Nordeste - FAINOR-Brasil . E-mail: luareis1 @ hotmail.com

${ }^{3}$ Programa de Pós-Graduação em Memória: Linguagem e Sociedade-Universidade Estadual do Sudoeste da Bahia- - UESB-BahiaBrasil. E-mail: lucianauesb@yahoo.com.br
}

Recebido em: 30/10/2020

Aceito para publicação em: 20/03/2021

\section{Resumo}

Este ensaio examina os sentidos de velhice nas imagens da mulher idosa presentes em quatro contos infantis escritos pelos autores Jacob Ludwing Carl Grimm e Wilhelm Carl Grimm oferecendo uma reflexão acerca da noção sobre a velhice, diante da realidade demográfica do Brasil. Para tanto, analisamos a violência simbólica associada aos estigmas e rótulos relacionados à velhice e discorremos sobre o processo de envelhecimento populacional, notadamente, a feminização da velhice no espaço urbano e o papel social desempenhado pelas idosas. Dessa maneira, recorremos em nossa fundamentação teórica, às contribuições de autores que tratam da velhice, do poder e violência simbólicos, bem como aos aportes da Análise do Discurso de linha francesa.

Palavras-chave: Feminização da Velhice. Mulheres idosas. Imagem. Violência Simbólica

\section{Abstract}


This essay examines the meanings of old age in the image of the elderly woman presents in four children's stories written by the authors Jacob Ludwing Carl Grimm and Wilhelm Carl Grimm, offering a reflection on the notion of old age, in view of the demographic reality of Brazil. Under this, we analyze symbolic violence associated with stigmas and labels related to old age and discuss the process of population aging, notably, the feminization of old age in the urban space and the social role played by the elderly. In this way, we use, in our theoretical foundation, the contributions of authors dealing with old age, symbolic power and violence, as well as contributions from Discourse Analysis of the French line.

Keywords: Feminization of old age. Elderdly woman. Image. Symbolic Violence

\section{Resumen}

Este ensayo examina los significados de la vejez a partir del análisis de la imagen de la anciana presentes en cuatro cuentos infantiles escritos por los autores Jacob Ludwing Carl Grimm y Wilhelm Carl Grimm, ofreciendo una reflexión sobre la noción sobre la vejez, en vista de la realidad demográfica de Brasil. Por lo tanto, analizamos la violencia simbólica asociada a estigmas y etiquetas relacionadas con la vejez y discutimos el proceso de envejecimiento de la población, en particular, la feminización de la vejez en el espacio urbano y el papel social desempeñado por los ancianos. De esta manera, utilizamos, en nuestra base teórica, las contribuciones de autores que tratan sobre la vejez, el poder simbólico y la violencia, así como las contribuciones del Análisis del discurso de la línea francesa.

Palabras clave: Feminización de la vejez. mujeres de edad avanzada. Imagen. Violencia simbólica

\section{Introdução}

Enfim, a sociedade destina ao velho seu lugar e seu papel levando em conta sua idiossincrasia individual: sua impotência, sua experiência; reciprocamente, o indivíduo é condicionado pela atitude prática e ideológica da sociedade em relação a ele. Não basta, portanto, descrever de maneira analítica os diversos aspectos da velhice: cada um deles reage sobre todos os outros e é afetado por eles; é no movimento indefinido desta circularidade que é preciso

A feminização da velhice é um fenômeno que implica em uma maior e melhor longevidade das mulheres se comparada aos homens. Neste 
encadeamento, abarca-se o papel social desempenhado pelas idosas, sobretudo, no espaço urbano. São novas funções exercidas por elas e que promovem impactos positivos no âmbito familiar e na economia. Nesta perspectiva, as cidades são apreendidas pelas mulheres idosas na sua imaterialidade. Ou seja, não necessariamente como trabalhadoras assalariadas, porém estão presentes exercitando um reordenamento social que aponta para as subjetivações do espaço urbano e as temporalidades que vão se constituindo (CORREA, 2016).

No entanto, em meio a profundas mudanças sociais e demográficas, reconhece-se que na velhice os idosos tendem a sofrer, de alguma forma, violência simbólica. Isso afeta diretamente as mulheres, pois as estatísticas oficiais mostram que é recorrente o uso de variados tipos de violência contra elas durante todo ciclo de suas existências. O Atlas da Violência (2020) indica que a violência letal contra a mulher pode ser considerada o resultado final e extremo de uma série de violências sofridas. No estudo realizado sobre o assunto, Cunha (2007) informa que a violência é especificamente de gênero ao considerar a população adulta e ela é contra a categoria que se inscreve de forma subordinada no quadro dessas relações. Dessa maneira, as mulheres idosas estão subjugadas a esse tipo de violência e ela é praticada, na maior parte das vezes, por familiares e no âmbito privado.

Neste contexto, a violência simbólica aparece com diversas conformações, normalmente, está presente nas falas, nas supostas "brincadeiras" caseiras e nos ditos populares. Para essa análise, ela é notada nos contos infantis quando a figura da idosa se associa a uma "velha" feia, má, desdentada, com uma fisionomia ameaçadora e desleixada, com deficiência física como um elemento que provoca o medo.

É fundamental observar que a língua está ligada a história de uma sociedade, de uma coletividade. Os discursos não são desprendidos do pensamento social e dominante em cada época. Orlandi (2015) comenta que nas 
palavras constam os sentidos de formações discursivas em suas relações. A linguagem em forma de discurso não é insenta, mas é atravessada por ideologias.

Para esta pesquisa, foram estudados os contos infantis escritos por Jacob Ludwing Carl Grimm (1785-1863) e Wilhelm Carl Grimm (1786-1859), no século XIX, mais conhecidos como os irmãos Grimm. As histórias analisadas foram: A Branca de Neve e os Sete Anões, João e Maria, Rapunzel e também os Seis Criados. Nelas, estão presentes falas e conversas que estigmatizam a mulher idosa e, dessa forma, preconceitua a velhice. Com isso, primou-se por averiguar nos contos infantis, selecionados previamente, a identidade da mulher idosa e a violência simbólica contidas nos presentes diálogos e como agressões similares são reiteradas no cotidiano na contemporaneidade.

Por conseguinte, as conceituações sobre a velhice são referendadas pela sociedade e estão carregadas com uma definição negativa. Isso reforça a visão da velhice como um declínio e indica que quem envelhece fracassa. Essas concepções possibilitam o exercício da violência simbólica que é também travestida de cuidado e de zelo por meio das pessoas mais próximas. A memória discursiva favorece a formulação de sentidos que estão imersos nas formações discursivas concebidas ao longo do tempo. Essas entram em funcionamento à medida que são estabelecidas as acepções com relação ao envelhecimento.

As mulheres idosas internalizam as visões alusivas a velhice, que são incorporados nos diferentes discursos e reproduzidos pela sociedade. $\mathrm{Na}$ maior parte das vezes, elas não percebem ou não têm possibilidades de se defenderem de situações ultrajosas. À vista disso, torna-se fundamental avaliar as questões que norteiam essa conjuntura, pois se trata de enunciados elaborados socialmente em que a beleza e a jovialidade estão em disputa com o envelhecimento da pele, do corpo, com o aparecimento das rugas faciais, do embranquecimento dos cabelos como componentes que censuram a velhice. 
Nesta compreensão, o presente estudo tem por objetivo perscrutar quais os discursos que permeiam a construção da velhice e como esses estão consubstanciados nos contos, nas falas, nos diálogos e perpetuam a ideia da velhice como algo que deve ser evitado indo na contramão de um processo natural para a humanidade.

\section{Metodologia}

Para esta investigação usou-se o método de Análise do Discurso, de linha francesa. Os contos infantis escolhidos para estudo foram: A Branca de Neve e os Sete Anões, João e Maria, Rapunzel e o conto os Seis Criados escritos por Jacob Ludwing Carl Grimm e Wilhelm Carl Grimm. Neles, observaram-se os atributos destinados à mulher idosa e como essas características podem percorrer os sentidos nas materialidades discursivas sobre a velhice. Esse estudo faz parte do projeto de pesquisa aprovado no Comitê de Ética protocolado com número CAAE 20065219.0.0000.5578.

Por meio de uma busca realizada na internet, no site Www.grimmstories.com, tivemos acesso a coletânea de todas os contos infantis escritos pelos referidos autores. Em seguida, foram selecionados 200 (duzentos) contos infantis. Nestes, foram verificados, por meio da ferramenta de busca do navegador, quais continham a palavra velha. A seleção, inicialmente, foi com base na maior incidência dessa expressão relacionada a mulher idosa. Após essa exploração, 04(quatros) contos foram separados e estudados, pois apresentavam a figura da idosa como uma vilã nos enredos. Isso posto, buscou-se entender as particularidades que fazem com que essa imagem esteja impregnada dos sentidos nocivos que acompanham o significado da própria velhice.

É fundamental destacar que em todos os contos apreciados, o personagem idoso, malvado e sem beleza aparente se refere à mulher. Portanto, percebe-se como o gênero feminino, na velhice, é abordado em cada história. Com isso, nota- 
se que as características destinadas às personagens se relacionam com as "adversidades" que são socialmente definidas como inerentes ao processo de envelhecimento e, desse modo, observa-se um encadeamento com a violência simbólica. Nos contos, esse tipo de violência se concatena com a depreciação da aparência física e com a descrição de ações inaceitáveis continuamente marcados pela expressão "velha" como agravante para as condutas que geraram sofrimentos para outras pessoas mencionadas nas narrativas infantis.

\section{A feminização da velhice}

O envelhecimento populacional é uma realidade brasileira. Assim, a partir da década de 1950, o Brasil teve seu perfil demográfico modificado em conformidade como o processo de urbanização que corroborou o advento da população migrando para as cidades e a sociedade deixa de ser majoritariamente rural.

Nesta situação, verifica-se uma diferenciação quando se trata da expectativa de vida ao nascer entre homem e mulher. Uma pessoa nascida no Brasil, em 2018, tinha expectativa de viver, em média, até os 76,3 anos. A expectativa de vida dos homens aumentou de 72,5 anos em 2017 para 72,8 anos em 2018, enquanto a das mulheres foi de 79,6 para 79,9 anos (IBGE, 2018).

Aliado a esse fenômeno, a Transição Demográfica se acelerou e a taxa de fecundidade que consiste em uma estimativa do número médio de filhos que uma tem mulher durante sua vida, diminuiu. Com o passar do tempo as taxas de natalidade também começaram a cair. Com efeito, existe no país um acelerado envelhecimento populacional e uma maior longevidade.

Segundo dados da Pesquisa Nacional por Amostra de Domicílios Contínua - Características dos Moradores e Domicílios, divulgada pelo Instituto Brasileiro de Geografia e Estatística (IBGE) em 2017, a população brasileira manteve a tendência de envelhecimento dos últimos anos e ganhou 4,8 milhões de idosos 
desde 2012, expressando a marca dos 30,2 milhões (em 2012, as pessoas com 60 anos ou mais somavam 25,4 milhões). As mulheres são maioria significativa nessa faixa etária, totalizando 16,9 milhões (56\% dos idosos), enquanto os homens idosos são 13,3 milhões (44\% do grupo).

Em consequência dessas transformações, é vital observar que o fenômeno da feminização da velhice no Brasil é cada vez mais crescente. Essa população de 60 anos e mais tem crescido, sobremodo, o número de mulheres, isto é, o gênero feminino é mais relevante quanto mais idoso é o segmento, notadamente, no espaço urbano (NERI, 2007).

Associado a maior longevidade das mulheres quando comparada com a dos homens, há uma expansão dessas idosas no mercado de trabalho (formalinformal, produtivo-improdutivo) e uma maior quantidade delas como chefes de família. Em termos percentuais, as famílias chefiadas por homens diminuíram de 72,6\% em 2001 para 59,5\% em 2015, enquanto o percentual de famílias chefiadas por mulher subiu de $27,4 \%$ para $40,5 \%$ no mesmo período (CAVENAGHI \& ALVES, 2018). No entanto, é imprescindível ponderar que a manifestação da presença feminina não se trata apenas de dados demográficos (DEBRET, 2004).

Diante dessa realidade, cabe observar qual o papel social desempenhado pelas mulheres idosas no contexto da feminização da velhice. Concebe-se o espaço geográfico como produto, reflexo, meio e condição de reprodução social e que acontece também no domínio do cotidiano. Isso permite que seja criado um gama de acepções e coerência que são entrelaçados pela história, pela cultura e estabelecem identidades, pois é o lugar onde a vida ocorre. Para Carlos (2007) a relação do homem com o mundo tem, pelo menos, dois sentidos: a produção da humanidade do homem e a reproudção constante do próprio mundo.

Nesta perspectiva, as mulheres idosas estão participando do espaço urbano de várias maneiras. Para tanto, elas têm assumido papéis primordiais na sociedade moderna. Sabe-se que, anteriormente, algumas atividades não eram designadas a 
elas. O comando da casa, por exemplo, sempre foi uma incumbência masculina ainda que o serviço doméstico estivesse constantemente outorgado às mulheres. Contudo, nessa fase da vida, essas atribuições estão sendo redefinidas.

Para as idosas casadas e para àquelas em que seus esposos estão enfermos ou morreram, elas têm se responsabilizado pelo governo do lar. Cavenaghi \& Alves (2018) comunica que "os tipos de família estão muito relacionados com a idade [...] a maior proporção dos homens chefes está nas idades mais jovens, enquanto a maior proporção de mulheres chefes está nas idades mais avançadas". Em outras situações, são as avós que muitas vezes, têm assumido as atribuições referentes aos pais e tomam para si todos os cuidados com as crianças.

Algumas idosas dividem seus lares com filhos e filhas que retornaram à casa dos pais após o divórcio. No entanto, são elas que também mantêm financeiramente o lar por meio do recebimento de sua aposentadoria. Nessa direção, promovem uma reordenação na concepção e no significado de envelhecer, ainda que não percebam esse processo. Não obstante, o papel social das mulheres vai se transformando como o passar do tempo, mesmo que continuem conectadas aos cuidades com a casa e a família.

A queda na renda do trabalho formal impulsiona as idosas a terem uma renda extra que habitualmente estão ligadas as tarefas artesanais. Essas atividades não eram desempenhadas na juventude por falta de tempo e, agora, conseguem exercê-las e, comercializar os produtos confeccionados. Algumas alternativas são buscadas para minimizar os impactos da diminuição da renda, tais como: passar ferro em roupas de outras famílias, fazer pequenos ajustes em vestimentas, fabricar bolos caseiros, serem vendedoras de produtos de beleza e àqueles referentes ao lar, entre outros exemplos.

Destarte, elas se permitem uma reinserção na cidade contemporânea de forma imaterial, pois não representa expressamente a volta ao trabalho remunerado nem as rotinas do trabalho fora de casa. É um processo de 
reintegração simbólica aos espaços da cidade, posto que, há uma reinvenção nas formas de gerir o tempo, o trabalho, o lazer, a convivência, os lugares e os vínculos sociais (DEBRET, 2004). É preciso assimilar que a velhice se tornou um assunto feminino e, como tal, as estratégias para uma maior visibilidade das mulheres idosas têm sido as mais variadas possíveis. Por isso, as redes de apoio desfrutam de um crescimento quando essas decidem que viver em coletividade as ajudam a reconstruírem suas vidas e seu cotidiano.

Vê-se que a idosa redefine os significados do envelhecimento e o transforma em um período da vida a ser vivido de maneira mais madura e proveitosa (DEBRET, 2004). Isto posto, é fundamental pensar sobre a produção da velhice, pois as idosas estão cada vez mais presentes nas áreas urbanas, ocupando espaços (materiais e imateriais), no mercado de trabalho, especialmente, na informalidade. Elas são assíduas nas universidades e nos grupos de convivência, por exemplo.

Neste âmbito, não há como desconsiderar as especificidades do organismo humano. Dessa maneira, apresentam-se as mudanças não apenas comportamentais, mas físicas e emocionais que alteram as relações com o dia-adia, com o mundo e outras formas de enxergar a si e os outros. As alterações no período do envelhecimento são reais, visíveis, porém não são determinantes nem excludentes.

Sabe-se que no período da senilidade, perde-se a robustez e o vigor característicos da mocidade. É comum que os idosos mantenham um compasso mais lento, com menor agilidade. As dificuldades de locomoção aumentam, aceleram-se as limitações da visão e, em consequência disso, todas as atividades precisam ser encaradas por uma outra perspectiva e estruturação. Com isso, os idosos (as) necessitam de um tempo maior para adaptar-se as limitações naturais do envelhecimento e as diversas realidades impostas pelas condições econômicas e 
emocionais. Afinal, o envelhecimento é a perda continua de adaptabilidade, o que resulta em uma crescente instabilidade (JEFFERY, 2001).

Todavia, a problemática a ser exposta é que a velhice acaba sendo deliberada pelo momento histórico e social na qual está inserido e dessa forma, vários dissabores podem ser experimentados nessa fase. Isto é, na velhice como em qualquer idade suas condições são prescritas pela sociedade a qual pretence (BEAUVOIR, 2018). Então, cabe atinar como a sociedade contemporânea percebe a velhice e o sujeito idoso, nesse caso, a mulher idosa. A velhice é uma construção social, por isso está recheada de simbolismo, significações, e concepções que a define.

Nesse percurso, a identidade social das mulheres idosas é definida em função das muitas maneiras de experienciar a velhice. $\mathrm{O}$ fato de apresentar maior longevidade, e, possivelmente, uma maior participação na vida moderna, pode colaborar para novas experiências nesse período. Neri (2007) avalia que a feminização aponta para mudanças nas normas etárias e de gênero que conduzem os comportamentos das mulheres idosas, as relações intergeracionais e as permutas de apoio material e afetivo entre as gerações.

Diante disso, outro aspecto importante a ser observado é o incentivo ao consumo pela mídia. Vive-se em um mundo globalizado em que existe uma aceleração com relação a oferta de serviços e produtos designados para essa categoria social. Sibila (2011) reitera que um conjunto de produtos é comunicada continuamente com uma eloquência especializada em garantir as mais alucinadas certezas. De igual modo, em virtude do aumento de idosos(as) é crescente os múltiplos serviços ofertados para atender aos desafios do envelhecimento e os fazê-los usufruírem de maior qualidade de vida.

Assim sendo, é perceptível uma gama de equipamentos de alta tecnologia nas várias áreas para atendê-los com rapidez e conforto desde os cosméticos rejuvenescedores, os remédios "milagrosos" aos aparelhos que prometem ajudá- 
los a terem uma vida mais eficiente, segura e tranquila. Silvertsone (2005) diz que a mídia usa a efemeridade para estimular o consumo. Para tanto, as fantasias devem ser oferecidas e corporificadas nas imagens das propagandas e não podem ser satisfeitas, mas sustentadas eternamente.

Essa categoria social é cada vez mais estimulada ao consumo de bens que reproduzem os padrões de beleza criados e manipulados pela sociedade e pelo mercado de trabalho. Silverstone (2005) declara que a mídia oferece mercadorias que fazem parte de um alienante sistema de produção com o intuito de criarmos o senso que temos de nós mesmo.

Com isso, constata-se que as produções midiáticas usam idosos(as) nas propaganda para aproximar-se dessa categoria com a finalidade de os atrelarem ao mercado consumidor e movimentar a economia. A construção da velhice pela sociedade tende a determinar o consumo de certos produtos associado aos processos de rejuvescimento e escamoteamento da velhice.

Para Haddad (2016), as condições objetivas de existência e as representações sobre a velhice são reflexos das relações, processos e estruturas do capitalismo. $\mathrm{O}$ idoso, de forma geral, não é tratado como um ser independente, lúcido com direitos e deveres, mas é retratado a semelhança de um objeto, é descaracterizado.

Neste encadeamento, compreende-se que as mulheres idosas, principalemnte após a aposentadoria, quando se afastam do mercado de trabalho formal e ao se distanciarem do espaço público têm a sua sociabilidade debilitada, posto que, foi regularmente construída, mormente, em conformidade com relações de trabalho. Para tanto, dispõe-se que a vida moderna espelha uma lógica pautada na produtividade econômica e a sujeição dos indivíduos a ela (DEBERT, 2004).

Neste contexto, é preciso pensar sobre as definições da velhice construídas historicamente, de preferência, da imagem que é mostrada sobre os idosos, especialmente, no tocante ao gênero feminino. Existem diversas crenças, 
ideologias, preconceitos e acepções que norteiam a velhice. Essas são produzidas, acolhidas socialmente e transmitidas às crianças, adolescentes e jovens.

$\mathrm{Na}$ sua maioria, singularmente no Brasil, a ideia sobre a velhice é comunicada pela mídia televisa, pela religião, pela arte, por meio da literatura e internet e, precipuamente, encontra abrigo na família e nos grupos sociais. Afinal, as pessoas tendem a confiarem mais em princípios usuais com os quais nasceram e cresceram e muito menos em argumentações contrárias a isso (MILL, 2006).

Por consequência, muitas dessas ideias e ensinamentos difundem o receio de envelhecer, de tornar-se velho, pois, geralmente, se associa a dependência, a saúde frágil, a solidão e a perda da dignidade. Isso possibilita a criação de preconceitos e estereótipos que resultam em conclusões céleres e sem fundamentos quanto a produtividade e, periodicamente, a competência dos idosos. Ao apresentar a formulação sobre a velhice, Neri (2003) diz que o conceito que prevalece sobre a velhice é negativo, quer analisado pela ótica individual ou social.

Mediante essas considerações, entende-se que as mulheres são sudordinadas a vários tipos de agressão e a violência simbólica é uma delas. Dos contos infantis às falas e ditos populares percebem-se expressões que estão permeadas da violência simbólica e essa é multifária e afeta diretamente a mulher idosa, posto que, muitas vezes elas não identificam as variadas situações violentas a que são expostas.

\section{Imagem, contos infantis e violência simbólica na velhice}

A violência e o envelhecimento humano são intrínsecos à humanidade. No espaço urbano é comum observar o alto índice de violência e as suas mais numerosas facetas. Dentre elas, as agressões contra a mulher têm aumentado nas 
distintas classes sociais. Na análise de Saffioti (2012) a violência é o rompimento de qualquer forma de integridade da vítima seja essa física, psíquica, sexual e moral.

Sabe-se que a violência física é um ato repugnante e passível de punição. No entanto, existem outras formas de hostilidade que são extremamente perigosas, perversas, sutis e não são encaradas danosamente como a violência física. Talvez porque, historicamente, as mulheres são alvos da coação, da humilhação, sobretudo, pelos homens (CUNHA, 2007). As mulheres idosas sofrem ataques e nem sempre elas os distinguem como violência.

Dessa forma, verifica-se que há um poder simbólico que é exercido sobre um determinado grupo de pessoas ou classe. Bourdieu (1989) afirma que o poder simbólico é como uma dominação invisível o qual só pode ser exercida com a cumplicidade daqueles que não querem saber que lhe estão sujeitos ou mesmo que o exercem. Assim, às idosas destina-se a acreditar na concepção de velhice que é estabelecida pela sociedade vigente. Para o exercício desse tipo de controle usa-se a linguagem, pois ela exprime um discurso, uma vez que está carregada de noções que norteiam a velhice e as suas complexidades.

A língua está desnuda na memória, nos acontecimentos, nas ilustrações e nos diálogos. Ela é marcada pelo momento social e econômico de uma coletividade. Para Pêcheux (1999, p.46), “[...] a memória discursiva seria aquilo que, em face de um texto que surge como acontecimento a ler, vem restabelecer os 'implícitos' (quer dizer, mais tecnicamente, os pré-construídos, elementos citados e relatados, discursos transversos, etc.)". À vista disso, os pareceres sobre a velhice estão inscritos na memória, e como tal, ela é viva e, consequentemente, se consolida nas práticas exercidas no cotidiano.

Os discursos que se referem à velhice são repletos de elementos fabricados para invisibilizar os aspectos naturais do processo de envelhecimento. Ou seja, em alguns deles quando dizem a respeito da velhice possuem a sua própria negação, pois o sujeito idoso não é aceito como tal, mas como deveria ser. Têm-se os 
funcionamentos discursivos por meio do qual a memória se materializa no discurso (INDURSKY, 2011). Observa-se que a imagem que serve de representação do idoso(a) se pauta, usualmente, na suposição da "eterna" juventude, da altivez e agilidade da mocidade.

Neste artigo, conforme indicado anteriormente, serão analisados os diálogos que expõem a imagem da mulher idosa nos seguintes títulos: A Branca de Neve e os Sete Anões, João e Maria, Rapunzel, bem como os Seis Criados. Neles, a "velha" é retratada como uma personagem maléfica e que está a todo momento punindo ou fazendo alguém sofrer. Concomitantemente, expõe a figura de uma senhora idosa que está atrelada a alguma conduta não recomendada, geralmente, causando a desventura de um ou mais personagens. Nas conversações dos referidos contos são usuais termos que indicam sobre a aparência física de uma determinada idosa e, costumeiramente, tipificada com argumentos depreciativos. Neste ensejo, ao olhar para algumas histórias da literatura infantil esse tipo de identificação é recorrente.

Com isso, desde a mais terna infância passa-se a conhecer as expressões: feia, mal vestida, ruim, bruxa, esquelética, má, infeliz, decrépita, cheia de rugas e com um corpo em decadência como representando a mulher idosa. Siliba (2011) pondera que há sinais de derrota na insana luta para se parecer mais jovem, pois as rugas se tornaram condenáveis. Esses são apenas alguns dentre outros estereótipos e estigmas que são postos sob a idosa, uma vez que nesses contos infantis elas raramente são protagonistas, mas repetidamente simboliza uma personagem que causa espanto ou terror.

Desarte, identificam a mulher idosa e a velhice de uma forma cruel e desumana. Nota-se que é transmitida a noção depreciativa da fisionomia de uma senhora idosa e, em função disso, persiste, por exemplo, no imaginário social que beleza e velhice são inconciliáveis. Nessas histórias, há o relato de crianças e de adolescentes que ficaram reclusas ou que sofreram malefícios e/ou castigos 
corporais por causa de uma ação que foi realizada por uma senhora idosa indicando que era uma "velha".

Nota-se que em trechos da história da Branca de Neve e os Sete anões apresentam a rainha travestida de idosa para se aproximar da personagem principal. A narrativa cita que uma rainha prepotente, disfarçada de "velha", tentou várias vezes se aproximar para matar a protagonista, no entanto, não conseguiu completar seu intento.

Constata-se, no texto, que ao se transfigurar em uma velha, ela despertou sentimentos em Branca de Neve e um deles foi considerar a "velha" honesta e que não faria mal a ninguém. Porém, durante o desenrolar da trama, a rainha metamorfoseada em idosa é tratada como uma "velha" que não tem um procedimento apropriado. Uma das características dessa idosa é a ausência de beleza e isso é a causa da inveja por Branca de Neve, uma vez que esse atributo é destinado apenas a protagonista do conto infantil.

Em outros momentos são explanadas as seguintes interlocuções:

- "Fez uma poção venenosa, que colocou dentro de uma maçã, e transformou-se numa velhinha maltrapilha. Pouco depois, a velha maltrapilha chegou perto da janela da cozinha". No trecho subsequente a esses acontecimentos diz que “[...] a Branca de Neve estendeu a mão e pegou a metade da maçã envenenada e ao dar uma mordida, caiu morta no chão. A rainha deu um olhar cruel, uma gargalhada terrível". Essas informações sugerem a malignidade de uma senhora idosa. Isso tende a induzir o leitor a constituir uma visão deturpada da velhice como sujeitos promotores de atos que são ilegítimos e impiedosos.

Ao mesmo tempo, deixa-se transparecer que a formosura não é um constitutivo de quem envelhece. A ideia implícita é que a velhice está em contradição com a juventude quando transcreve os aspectos físicos dos personagens mais jovens. A formação da identidade de uma pessoa envelhecida 
perpassa por algumas condições, entre elas, a aparência física como elemento pujante.

Com isso, observa-se que o corpo da mulher idosa, nessa história infantil, é ausente de beleza que possa ser admirada e esse condicionante atinge sua identidade a ponto de desejar a beleza da Branca de Neve. Para D’Alencar (2017) o corpo tem sido uma das grandes preocupações humanas e que mesmo pertencendo ao indivíduo, a sociedade é quem determina a maneira de apresentálo, de cuidar dele. Verifca-se como o corpo signfica, textualiza e está carregado de significantes distintos (ORLANDI, 2017). Assim, o corpo é visto como um discurso, posto que tem representatividade social.

Na história de João e Maria consta algumas conversações que são:

- "[...] abriu-se a porta da casinha e saiu uma velha muito feia, mancando, apoiada em uma muleta. João e Maria se assustaram, mas a velha sorriu, mostrando a boca desdentada".

-“A velha fingia ser muito boa, mas na verdade era uma bruxa muito má, que atraía as crianças; para isso havia construído a casinha de pão-de-ló. E, quando caía em suas mãos alguma criança, ela matava-a, cozinhava-a e comia-a".

Neste trecho, tem-se a representação relativa à idosa. Notam-se referências sobre o seu semblante, seu corpo descrito com uma deficiência e sem condições de um caminhar livremente. Logo, transcreve a figura de uma pessoa macabra e associada a atitudes desprezíveis.

Desse modo, a velhice é desenhada com noções sombrias que são fixados na memória. Portanto, ao se pensar sobre o envelhecimento esses aspectos serão rememorados. Diante disso, Orlandi (2017) pondera que para que haja memória é preciso que o acontecimento, ou o conjunto de conhecimentos registardos saia da indiferença, que ele deixe o domínio da insignificância. Nesta perspectiva, a memória faz retomar as referências que foram apreendidas sobre o que é um idoso 
e, de igual modo, acerca do que a velhice representa. Os contos em questão acabam por moldar o envelhecimento e o dota de significação.

À vista disso, a velhice é marcadamente destinguida pela decadência física que é bem delineada no relato do conto. A representação social da velhice está ligada aos aspectos repulsivos aluvisos ao processo de envelhecimento físico que faz parte de um trancurso comum ao ser humano. Ela tem sido hostilizada por não conter o frescor juvenil e, dessa forma, no avançar da idade, as modificações corporais, a fragilidade física - contrário a virilidade, a flexiblidade e destreza da mocidade - "justificam" as imagens negativas no tocante o idoso(a).

A pesquisa seguinte se refere ao conto de Rapunzel que relata a história de uma jovem aprisionada em uma torre por uma "velha" que para ir até ao topo da torre solicitava que Rapunzel jogasse suas tranças que eram utilizadas como meio de transporte. Esse aprisionamento causava sofrimento a uma jovem mulher, pois não tinha contato com mais ninguém a não ser com a senhora idosa. Nisso, verifica-se o infortúnio experimentado por uma moça que fora provocado por uma mulher "velha". Em uma parte da história ela é salva por um príncipe. Durante esse salvamento, existe uma conversação que exprime:

-“Ele, dizia a jovem: és mil vezes preferível à "velha” senhora.

Mais adiante, e por ter sido enganada, a "velha" dá um castigo à Rapunzel:

- “Na sua fúria, agarrou Rapunzel pelos cabelos e esbofeteou-a. Depois, com a outra mão, pegou uma tesoura e tec, tec! cortou as belas tranças, largandoas no chão. $\mathrm{O}$ fato de ter cortado as tranças impedia o príncipe de chegar até a torre. Não contente, a malvada levou a pobre menina para um deserto e abandonou-a ali, para que sofresse e passasse todo tipo de privação.".

Mais uma vez, confirma-se a mulher idosa sendo rotulada como uma pessoa que causa sofrimento e infelicidade. Ou melhor, o comportamento exercido pela mulher envelhecida não é adequado, mas inapropriado e atroz. Essa linguagem não apenas aponta as características da personalidade de um 
personagem, mas está impregnada de sentidos sobre a mulher idosa, afinal a linguagem enquanto discurso não é imparcial, não é inócua, mas manifesta ideologias (BRANDÃO, 2012).

Neste percurso, torna claro uma disputa por causa da beleza com a jovem Rapunzel. Para Wolf (2020) as mulheres idosas temem as jovens e vice-versa e o mito da beleza mutila o curso da vida. Com isso, percebe-se a repulsa do seu próprio corpo e, em resultado disso, subordinava outra mulher ao isolamento. Neste caso, agrava-se ainda o fato da jovem ter a atenção de um príncipe moço, forte, belo e diposto a amar.

D’Alencar (2017, p. 168) considera que “[...] o corpo se emancipa como ponto de referência no espaço e no tempo, transformando-se em essência, substrato da identidade e, por extensão, da personalidade". Assim, têm-se as múltiplas visões sobre a velhice que norteam a literatura infantil e a cada época essas impressões e discursos são repassados e perpetuados na história afetando a imagem que cada idoso(a) tem de si mesmo.

Na história intitulada Os Seis Criados, dos mesmos autores, identifica-se uma rainha idosa que pratica atos violentos contra os pretendentes de sua filha jovem e bela. A personagem dificulta a aproximação dos aspirantes que desejam noivar e casar com sua filha. Em um fragmento do texto a rainha é descrita como: "[...] a "velha" rainha só se preocupava em atrair os homens para prejudicá-los. $\mathrm{Ou}$ "[...] todo pretendente que aparecia, ela informava-o de que, se quisesse casar com a filha, devia antes decifrar uma adivinhação; se não o conseguisse, teria que morrer".

Durante a narrativa, depara-se com essa personagem impondo obstáculos para que o jovem interessado não consiga casar-se. As ações praticadas pela "velha" rainha eram portadoras de infortúnio para o casal. Nos contos, há sempre uma associação entre a "velha" e as más ações em contraste com as boas práticas dos mais moços. Assim, os efeitos desse tipo de discurso alusivo à velhice, em 
diferentes situações, podem possuir repetições que foram expostos em outras materialidades discursivas. Indursky (2011, p. 69) alerta que: “[...] trata-se ainda da retomada de saberes já-ditos em outro discurso, em outro lugar e cujo eco ressoa no discurso do sujeito".

Dessa forma, é ostentada a figura do mal, da tristeza, da incapacidade de amar como atributos do processo de envelhecimento. Nisso, demonstra-se que na velhice é comum encontrar modos não desejáveis e inapropriados em discrepância com um jovem -um príncipe - que é descrito como um personagem de práticas salvadoras e exemplares, especificado nos contos de Rapunzel e Os Seis Criados.

De igual modo, as moças identificadas como princesas estão em contraste com a personificação física da idosa que se refere à feiura, amorfa, maltarpilha e com deficiência física. "Nesse sentido, além de um capital físico, o corpo é, também um capital simbólico, um capital econômico e um capital social" (GOLDENBERG, 2015). Os aspectos corporais se tornam uma marca expressiva do perfil feminino estipulado pela sociedade que tem seus parâmetros definidos e pautados em torno da formosura e perfeição física.

Esses são exemplos revelam como a mulher idosa é retratada nessas histórias infantis, como os estigmas da velhice são desenvolvidos e, consequentemente, vão se disseminando e produzindo conceituações nefastas, distorções e manipulações quanto ao processo natural de envelhecimento humano perpassada entre gerações. Pêcheux (2015, p.56) indica a potencialidade dos discursos quando afirma:

[...] todo discurso é o índice potencial de uma agitação nas filiações sócio-históricas de identificação, na medida em que ele constitui ao mesmo tempo um efeito dessas filiações e um trabalho (mais ou menos consciente, deliberado, construído ou não, mas de todo atravessado pelas determinações inconscientes) de deslocamento do seu espaço.

Associada a isso, a figura da mulher idosa enfrenta desafios, pois os temas que envolvem a velhice são permeados dos já-ditos e do interdiscurso que são 
rememorados e associados ao processo de envelhecer e, assim, vários sentidos sobre o tema ecoam em diferentes momentos. Dessa maneira, entende-se que toda vez em que os estigmas ligados à velhice são elencados e transcritos há uma retomada/ regualrização de sentidos que vão constituir uma memória que é social (INDURSKY, 2011).

Os enunciados sobre a mulher idosa materializados nos contos refletem a construção social da velhice que se move entre os diversificados enredos. Pêcheux (2018) avalia que o essencial não trata somente da natureza das palavras empregadas, mas também e, sobretudo, das construções nas quais essas combinam. Logo, ao abordar o tema da mulher idosa todos os fundamentos em torno da velhice são rememorados seja em que âmbito for.

Brandão (2012, p. 95) assevera que “[...] é a memória discursiva que torna possível toda formação discursiva fazer circular formulações anteriores, já enunciadas". Então, não existe discurso deslocado de constexto social e esse é absorvido pela memória social sempre que esse tema - a velhice - está sendo apreciado.

As inúmeras noções sobre a velhice estão atravessadas pelos componentes que dão significado a ela. Quer dizer, na perspectiva social a velhice é, muitas vezes, entendida por meio das definições relacionadas à sua negação. Ela está associada ao falecimento da produtividade e esse período da vida tem sido anunciado como sendo necessária a busca pela eficiência, pelo rejuvenescimento, pela autonomia, pois, dessa maneira, será associada a mocidade e, então, será enaltecida. A velhice será interpretada com base nas significações que estão presentes no imaginário social. Em função disso,

[...] resulta que a interpretação é necessariamente regulada em suas possibilidades, em suas condições. Ela não é um mero gesto de decodificação, de apreensão do sentido. A interpretação não é livre de determinações: não é qualquer uma e é desigualmente distribuída na formação social (ORLANDI, 2015, p.45). 
Neste panorama apresentado, constata-se que a violência simbólica está presente na velhice e nos heterogêneos discursos acerca da mulher idosa que são repetidos historicamente como nos contos avaliados e, ao mesmo tempo, pode passar despercebida ao identificar a idosa a demência, a inutilidade, a uma pessoa que não tem autonomia, por exemplo. Muitas vezes, as falas agressivas e humilhantes não são notadas pelas idosas que convivem com tais condições.

Na maioria das vezes, elas não distinguem as violências sofridas, pois são assimiladas socialmente tornando-se quase imperceptíveis. Neri (2003) aponta para o fato de que os idosos(as) acham comuns as formas de tratamento discriminatório a que são submetidos em diversas situações como no trabalho, na propaganda ou nos serviços de saúde, e chegam a encontrar explicações para tais circunstâncias. As mulheres, de alguma forma, sofrem violência simbólica durante sua existência. Desde as humilhações na infância, o bullying sofrido na adolescência que se estende até a velhice, de uma maneira velada ou não.

Com o passar do tempo, algumas definições desaparecem, outras permanecem relacionadas à percepção da velhice. No entanto, é contraditório como a sociedade enfrenta essa fase, pois ela é vista apenas como o fim da vida, ela é marcada como um evento estático, porém é, na verdade, um prolongamento de um processo (BEAUVOIR, 2018). Entretanto, a mulher, na velhice, continua a ter direitos, deveres e requer um tratamento digno como uma pessoa em qualquer idade.

Deste modo, a violência simbólica define-se, num primeiro momento, como uma violência dissimulada o que, diga-se de passagem, lhe confere poderes particulares e eficácia específica. Nota-se isso, nos contos infantis estudados, ao perceber como a mulher idosa foi identificada por meio das referências negativas quanto ao corpo feminino. Essa violência, então, é classificada como violência física mascarada, invisível e esquecida e tem por efeito, estabelecer a legitimidade de um discurso de um agente ou uma instituição Bourdieu (1989, p.7-8) a define: 
[...] violência simbólica, violência suave, insensível, invisível a suas próprias vítimas, que se exerce essencialmente pelas vias puramente simbólicas da comunicação e do conhecimento, ou, mais precisamente, do desconhecimento, do reconhecimento ou, em última instância, do sentimento.

Debret (2011) afirma que a negação da velhice impede a criação social de uma estética da própria velhice. Com frequência, as idosas são quem mais sofre com os apelidos pejorativos, com as "brincadeiras" constrangedoras quanto à sua beleza, seus cabelos brancos, suas rugas, sua lentidão natural do corpo envelhecido, sua distração, sua inaptidão quando se trata de tarefas específicas. Inversamente, a imagem do idoso é mais tolerável. Os homens ficam mais afastados das fragilidades do ser velho, pois o padrão da masculinidade está repleto de dominância, produzida socialmente. Basta reparar que em nenhum conto infantil investigado exibe um idoso como o personagem perverso.

Com relação às mulheres e, contrariamente ao padrão masculino, há uma clara demonstração das diversas servidões a que as mulheres são submetidas durante sua existência. Mill (2006) questiona: o que é o desejo de controle? É desejar exercê-lo principalmente sobre aqueles que lhes estão mais próximos, com quem passa a vida, com quem tem mais interesse em comum, e em quem, a independência em relação a sua autoridade mais comumente pode interferir em suas preferências individuais. De uma forma ou outra a divisão entre os sexos parece estar na "ordem das coisas" e funciona muito bem, pois está incorporado aos hábitos, pensamentos e ações diárias (BOURDIEU, 2012).

Por conseguinte, a figura da idosa fica extremamente exposta as variadas espécies de piadas, de menosprezo, de insignificância, dado que esse tipo de violência é avaliado como incomum, porque não se trata de uma agressão física necessariamente, é considerada sutil, até mesmo, mais branda. Vive-se em uma cultura que se pauta no belo, no corpo que deve ser perfeito, jovial, vigoroso e, nessa dinâmica, o que o cabe para a velhice e, em particular, para a mulher idosa, 
se traduz em esquisita, desajeitada, fora do padrão, lenta e descartável, dentro e fora do núcleo familiar. Além disso, os idosos, em geral, constituem uma categoria desprezada, vistos pelo decréscimo e, mais que isso, como a antecâmara da morte (NERI, 2003).

Verifica-se que as histórias infantis analisadas, costumeiramente, são contadas nas residências até mesmos pelas avós, particularmente, veiculadas no âmbito doméstico, em seus próprios lares. Esse tipo de literatura encontra-se nas escolas e são apreciados em momentos de lazer, de descontração. Ou melhor, não há o menor constrangimento em apresentar um perfil destrutivo da mulher idosa. Para Saffioti (1997) não é apenas o amor que é cultivado na família, mas também o ódio. Essa violência é nomeada como intrafamiliar. Cunha (2007) a classifica como uma das formas habituais de expressão da violência, pois acontece nas relações mais íntimas entre integrantes de um mesmo núcleo familiar e, correntemente, é dentro do lar que ela se manifesta.

Isto posto, esse tipo de agressão é evidenciado cotidianamente e é subsidiada com a imposição da sociedade quanto ao estilo de vida da idosa. Ou seja, a velhice é um diereito negado ou algo que deveria conservar-se oculto (SIBILA, 2011). Desse modo, se essa mulher estiver dentro dos padrões sociais que a caracterizem como moderna, ativa, e rejuvenescida, por exemplo, a manifestação da violência simbólica não será sentida ou não existirá. Caso contrário, são visíveis os constrangimentos, os insultos e a desconstituição da identidade da idosa o que lhe causa desconforto, tristeza, angústia e inconformidade. Para Beauvoir (2018) a sociedade ignora os abusos, a indecência e os dramas que não abalam seu equilíbrio, em virtude disso, não se importa com as crianças abandonadas e os velhos.

Essas exteriorizações da violência simbólica são legitimadas no discurso do cuidado e, até mesmo, do bem-querer. Nessa lógica, as próprias idosas que sofrem as agressões não verbalizam sua insatisfação e, ocasionalmente, nem concebem 
essas demonstrações como maléficas, pois acabam por compreender que existe o zelo, a dedicação e passam a se acostumar com as formas de tratamentos concedida pelos parentes.

Diante das ponderações, é possível salientar que a velhice para as idosas é atravessada pelas dificuldades do exercício de ser mulher. Desse modo, é possível que para elas estejam destinadas a sujeição, a exclusão, a discriminação e as diversas formas de violência. Aliado a isso, a sociedade propende a ratificar a dominação masculina (BOURDIEU, 2012).

Para tanto, a violência simbólica tende a manter a idosa sob o domínio do outro, de quem manda de quem determina como uma mulher dever ser, se comportar e suportar as adversidades da velhice. Nesta dinâmica, a morte social da mulher idosa pode estar sendo estabelecida e reforçada no mesmo espaço onde a feminização da velhice se institui. E, em meio a tudo isso, identifica-se pouca efervescência de políticas públicas para discutir o tema em questão, a quase ausência das fiscalizações legais do Poder Público, por ora, o silêncio das Instituições e, ainda, a carência de ações dos familiares na proteção das mulheres idosas.

\section{CONSIDERAÇÕES FINAIS}

Com o fenômeno de feminização da velhice, o Brasil conta um grande número de idosas no espaço urbano e novas atribuições vivenciadas por elas. Elas convivem com vários desafios nesse estágio da vida. Dentre eles, a violência simbólica que é experimentada no dia-a-dia, especialmente, no ambiente familiar. Associado a isso, tem-se enraizado no imaginário social que ser idoso (a) é um destino trágico, um ser incapacitado e, portanto, dificulta o pleno reconhecimento dessa categoria social como sendo digna de direitos no pleno exercício de seus deveres. 
Os contos infantis verificados tendem a identificar a mulher idosa com um perfil violento, injusto e causador de desdita, além de qualificar negativamente a idosa quanto a sua fisionomia. Isso vai produzindo efeitos, que se torna real e é reproduzido. Em função disso, a violência simbólica pode se tornar comum uma vez que a linguagem é reveladora das práticas sociais, sobretudo, com as mulheres.

Por vezes, as idosas não conseguem distinguir os atos violentos, pois interiorizam essas manifestações como habituais e costumeiras. Diante disso, é essencial discutir quanto às formas de vida a que as mulheres estão sendo condicionadas e, ao mesmo tempo, perceber as prisões das ideologias, dos padrões que têm sucumbido as mulheres, durante suas vidas, a todo tipo de violência. Para tanto, as reflexões expostas podem servir para novos debates em torno do tema com a finalidade de buscar alternativas para combater a invisibilidade do sujeito idoso e as mazelas sociais do envelhecimento.

\section{REFERÊNCIAS}

BEAUVOIR, Simone. A velhice. Tradução Maria Helena Franco Martins. 2. ed. Rio de Janeiro: Nova Fronteira, 2018.

BOURDIEU, Pierre. A dominação masculina. Tradução Maria Helena Künher. 11 ${ }^{\underline{a}}$ edição. Rio de Janeiro: Bertrand Brasil, 2012.

BOURDIEU, Pierre. O poder simbólico. Tradução de Fernando Tomaz. Rio de Janeiro: Bertrand Brasil, 1989.

BRANDÃO, Helena H. Nagamine. Introdução à análise do discurso. $3^{\underline{a}}$ ed. ver. Campinas, SP: Editora Unicamp, 2012.

BRASIL, IBGE. Estatísticas sociais, 2018. Disponível em

https://agenciadenoticias.ibge.gov.br. Acesso em 27 de outubro de 2020.

BRASIL, IBGE. Pesquisa nacional por amostra de domicílios continua- PNAD continua, 2017. Disponível em

https://www.ibge.gov.br/estatisticas/multidominio/condicoes-de-vidadesigualdade-e-pobreza/17270-pnad-continua.html?=\&t=o-que-e. Acesso em 27 de outubro de 2020. 
CARLOS, Ana Fani Alessandri. O espaço urbano: novos escritos sobre a cidade. São Paulo: LABUR Edições, 2007.

CAVENAGHI, Suzana; ALVES, José Estáquio Diniz. Mulheres chefes de família no Brasil: avanços e desafios. Rio de Janeiro: ENS-CPES, 2018. 120 p.; $21 \mathrm{~cm}$ (Estudos sobre Seguro, nํㅜㄹ).

CORREA, Mariele Rodrigues. Envelhecer na cidade. Revista Espaço Acadêmico. V.16 n. 184, setembro, 2016.

CUNHA, Tânia Rocha Andrade. O preço do silêncio: mulheres ricas também sofrem violência. Vitória da Conquista: Edições UESB, 2007.

D'ALENCAR, Raimunda Silva. Idosas no contexto da vida cotidiana: como percebem o corpo. In: D'ALENCAR, Raimunda Silva. A representação social na construção da velhice (org.) Ilhéus, BA: Editus, 2017.

DEBRET, Guita Grin. Velhice e tecnologias do rejuvenescimento. In:

GOLDENBERG, Mirian (org.) Corpo, envelhecimento e felicidade. Rio de Janeiro: Civilização Brasileira, 2011.

DEBRT, Guita Grin. A reinvenção da velhice: socialização e processos de reprivatização do envelhecimento. São Paulo: Editora da Universidade de São Paulo: FAPESP, 2004.

GOLDENBERG, Mirian (org.). O corpo como capital: estudos sobre gênero, sexualidade e moda na cultura brasileira. $3^{\underline{a}}$ ed. Rio de Janeiro: Estação das Letras e Cores, 2015.

GRIMMSTORES. Contos de Grimm Disponível em https://www.grimmstories.com/pt/grimm_contos/index. Acesso em 01 de junho de 2020.

HADDAD, Eneida Gonçalves de Macedo. A ideologia da velhice. 2ª edição. São Paulo: Cortez, 2016.

INDURSKY, Freda; Mittmann, Solange; FERREIRA, Maria Cristina Leandro (orgs). Memória e história na/da análise do discurso. Campinas, SP: Mercado das Letras, 2011.

INSTITUTO DE PESQUISA ECONÔMICA APLICADA - IPEA. Atlas da violência. Brasília: IPEA, 2020. Disponível em https:/forumseguranca.org.br/wpcontent/uploads/2020/08/atlas-da-violencia-2020.pdf. Acesso em 02 de outubro de 2020. 
JEFFREY, Peter. Remar contra a corrente: aspectos éticos do envelhecimento e de seu cuidado. Tradução de Bárbara Theoto Lambert. São Paulo: Edições Loyola, 2001.

MILL, John Stuart. A sujeição das mulheres. Revista Gênero. V.6, n.2, n 1, p. 181202, 1-2 sem. 2006, 181, Niterói.

NERI, Anita Liberalesso. Idosos no Brasil: vivências, desafios e expectativas na terceira idade. São Paulo: Editora Fundação Perseu Abramo, Edições SESCSP, 2007.

NERI, Anita Liberalesso. Atitudes e crenças sobre velhice: análise de conteúdo de textos do jornal O Estado de São Paulo publicados entre 1995 e 2002. In O. R. M. von Simson, A. L. Neri, \& M. Cachioni (Orgs.). As múltiplas faces da velhice no Brasil. Campinas, SP: Átomo Alínea, 2003.

ORLANDI, Eni Puccinelli. Análise de discurso: princípios e procedimentos. $12^{a}$ edição. Campinas, SP: Pontes Editores, 2015.

ORLANDI, Eni. Puccinelli. Discurso em análise: sentido, sujeito, ideologia. $3^{\text {a }}$ edição. Campinas, SP. Pontes Editores, 2017.

PÊCHEUX, Michel. Língua, linguagem, discursos. In: CARLOS, Piovezani; SARGENTINI, Vanice. Legados de Michel Pêcheux: inéditos em análise do discurso. São Paulo: Contexto, 2018.

PÊCHEUX, Michel. O discurso: estrutura ou acontecimento. Tradução Eni P. Orlandi. Campinas: Pontes Editores, 2015.

PÊCHEUX, Michel. Papel da memória. In: ACHARD, Pierre, DAVALLON; Jean; DURAND. Jean-Louis; PÊCHEUX, Michel; ORLANDI, Eni P. O papel da memória. Campinas: Pontes Editores, 1999.

SAFFIOTI, Heleieth Bongiovani. Gênero, patriarcado e violência. 11ª edição. São Paulo: Editora Fundação Perseu Abramo, 2012.

SAFFIOTI, Heleieth Bongiovani. Violência doméstica ou a lógica do galinheiro. In: KUPSTAS, Márcia (org.) Violência em debate. São Paulo: Moderna, 1997.

SIBILA, Paula. A moral da pele lisa e a censura midiática da velhice: o corpo velho como uma imagem com falha. In: GOLDENBERG, Mirian (org.) Corpo, envelhecimento e felicidade. Rio de Janeiro: Civilização Brasileira, 2011.

SILVERSTONE, Roger. Por que estudar a mídia? Tradução: Milton Camargo Mota. 2ª ed. São Paulo: Edições Loyola, 2005. 
WOLF, Naomi. O mito da beleza: como as imagens de beleza são usadas contra as mulheres. Tradução Waldéa Bracelos. 13ª ed. Rio de Janeiro: Rosa dos tempos, 2020.

\section{Agradecimentos}

À Fundação de Amparo à Pesquisa do Estado da Bahia - FAPESB.

Contribuição dos autores: Nádia Sampaio: Elaboração, discussão dos resultados, pesquisa bibliográfica Luana de Araújo dos Reis: Supervisão e desenvolvimento da pesquisa

Luciana Araújo dos Reis: Análise final dos resultados e revisão do texto 